\title{
Correction to: Incidence and Risk Factors for Severity of Postoperative Ileus After Colorectal Surgery: A Prospective Registry Data Analysis
}

\author{
A. Venara ${ }^{1,2,3}$ (D) $\cdot$ H. Meillat ${ }^{4} \cdot$ E. Cotte ${ }^{5,6} \cdot$ M. Ouaissi ${ }^{7}$ E. Duchalais ${ }^{3,8} \cdot$ C. Mor-Martinez ${ }^{9}$. \\ A. Wolthuis ${ }^{10}$ - J. M. Regimbeau ${ }^{11}$ - S. Ostermann ${ }^{12}$ - J. F. Hamel ${ }^{13} \cdot$ J. Joris $^{14} \cdot$ K. Slim ${ }^{15}$. \\ the GRACE Collaborative Group For Ileus Study
}

Published online: 28 January 2020

(C) Société Internationale de Chirurgie 2020

\section{Correction to: World J Surg https://doi.org/10.1007/s00268-019-05278-3}

In the list of participating investigators that appears in Acknowledgements, one of the investigators names appears incorrectly. Boudewijn $\mathrm{S}$ should be replaced by Smeets BJ.
Publisher's Note Springer Nature remains neutral with regard to jurisdictional claims in published maps and institutional affiliations.

The original article can be found online at https://doi.org/10.1007/ s00268-019-05278-3.

\section{A. Venara \\ auvenara@yahoo.fr}

1 Faculty of Medicine of Angers, Angers, France

2 Department of Visceral and Endocrinal Surgery (Service de chirurgie viscérale et endocrinienne), CHU Angers, 4, Rue Larrey, 49933 Angers Cedex 9, France

3 UMR INSERM U1235, TENS, The Enteric Nervous System in Gut and Brain Disorders, Institut des Maladies de l'Appareil Digestif, 1, Rue Gaston Veil, 44035 Nantes, France

4 Institut Paoli-Calmette, 232 Boulevard de Sainte Marguerite, 13009 Marseille, France

5 Department of Visceral Surgery, CHU Lyon, Centre Hospitalier Lyon-Sud, 69495 Pierre-Bénite Cedex, France

6 Université de Lyon, Lyon, France

7 Department of Visceral Surgery, CHU Tours, 2 Boulevard Tonnelé, 37000 Tours, France

8 Department of Visceral Surgery, CHU Nantes, 1 Place Alexis Ricordeau, 44000 Nantes, France

9 Department of Visceral Surgery, Clinique de l'Alliance, 1 Boulevard A Nobel, 37540 Saint Cyr Sur Loire, France
10 Department of Abdominal Surgery, UZ Leuven, Herestraat 49, 3000 Leuven, Belgium

11 Department of Visceral Surgery, CHU Amiens, Avenue Laennec, 80054 Amiens, France

12 Hirslanden Clinique La Colline, Geneva, Switzerland

13 Department of Methodology and Biostatistics, CHU Angers, 4 Rue Larrey, 49933 Angers Cedex 9, France

14 Department of Anesthesiology, CHU Liège, Domaine de Sart Tilman, Université de Liège, 4000 Liege, Belgium

15 Department of Visceral Surgery, CHU Clermont-Ferrand, 63003 Clermont-Ferrand, France 